\title{
Hunger Promotes Fear Extinction by Activation of an Amygdala Microcircuit
}

\author{
Dilip Verma ${ }^{1,4}$, James Wood ${ }^{1,4}$, Gilliard Lach ${ }^{1,2}$, Herbert Herzog ${ }^{3}$, Guenther Sperk' and Ramon Tasan ${ }^{*, 1}$ \\ 'Department of Pharmacology, Medical University of Innsbruck, Innsbruck, Austria; ${ }^{2}$ CAPES Foundation, Ministry of Education of Brazil, Brasilia, \\ Brazil; ${ }^{3}$ Neuroscience Research Program, Garvan Institute of Medical Research, Sydney, NSW, Australia
}

\begin{abstract}
Emotions control evolutionarily-conserved behavior that is central to survival in a natural environment. Imbalance within emotional circuitries, however, may result in malfunction and manifestation of anxiety disorders. Thus, a better understanding of emotional processes and, in particular, the interaction of the networks involved is of considerable clinical relevance. Although neurobiological substrates of emotionally controlled circuitries are increasingly evident, their mutual influences are not. To investigate interactions between hunger and fear, we performed Pavlovian fear conditioning in fasted wild-type mice and in mice with genetic modification of a feeding-related gene. Furthermore, we analyzed in these mice the electrophysiological microcircuits underlying fear extinction. Short-term fasting before fear acquisition specifically impaired long-term fear memory, whereas fasting before fear extinction facilitated extinction learning. Furthermore, genetic deletion of the $Y 4$ receptor reduced appetite and completely impaired fear extinction, a phenomenon that was rescued by fasting. A marked increase in feed-forward inhibition between the basolateral and central amygdala has been proposed as a synaptic correlate of fear extinction and involves activation of the medial intercalated cells. This form of plasticity was lost in Y4KO mice. Fasting before extinction learning, however, resulted in specific activation of the medial intercalated neurons and re-established the enhancement of feedforward inhibition in this amygdala microcircuit of Y4KO mice. Hence, consolidation of fear and extinction memories is differentially regulated by hunger, suggesting that fasting and modification of feeding-related genes could augment the effectiveness of exposure therapy and provide novel drug targets for treatment of anxiety disorders.
\end{abstract}

Neuropsychopharmacology (2016) 4I, 43I-439; doi: I 0.I 038/npp.20 I5.I63; published online I July 20 I 5

\section{INTRODUCTION}

Emotions, motivations, and reinforcement are a closely related, evolutionarily-conserved phenomena maintaining the integrity of an individual and promoting survival in a natural environment (Atasoy et al, 2012; LeDoux, 2012; Sternson, 2013). However, if such survival circuits are out of balance, maladaptation may arise and result in the development of anxiety disorders. Thus, a better understanding of fear and anxiety includes also the interaction with other lifesustaining brain circuitries and their reciprocal integration.

We therefore hypothesized that modulation of one survival circuit will provoke a significant impact on the other survival circuits. For instance, if a decrease in blood glucose signals that energy homeostasis is out of balance, release of hormones and activation of hypothalamic nuclei will be initiated (Balleine, 2005; Sohn et al, 2013; Williams and Elmquist, 2012). As a consequence, food intake and search for food will prevail and emotional behavior will be adapted accordingly. Indeed, recent

\footnotetext{
*Correspondence: Dr R Tasan, Department of Pharmacology, Medical University of Innsbruck, Institute of Pharmacology, Peter-Mayr-Strasse Ia, Innsbruck 6020, Austria, Tel: +43 5129003 7|207, Fax: +43 5 I2 9003 73200, E-mail: ramon.tasan@i-med.ac.at

${ }^{4}$ These first two authors contributed equally to this work.

Received 20 February 2015; revised 6 May 2015; accepted 28 May 2015; accepted article preview online II June 2015
}

experiments in Drosophila suggest a close relation between food intake and the formation of aversive memories (Hirano et al, 2013; Placais and Preat, 2013).

Here, we investigated the neurobiological effects of fasting on the different phases of mammalian fear processing in mice, in particular fear acquisition, consolidation, and, most importantly, fear extinction. The amygdala complex, located in the temporal lobe, is centrally involved in coordinating fear-related processes. It receives information about fearprovoking stimuli via thalamic and cortical afferents and regulates the resulting fear response by efferent projections targeting hypothalamus and brain stem (Ehrlich et al, 2009). The central amygdala (CEA) represents the major output station for generating an adaptive fear response. It consists of a highly elaborate micronetwork that receives afferent projections from the adjacent basolateral amygdala (BLA), intercalated cell masses, and also from more distant brain areas such as hypothalamus and brain stem. Recent evidence suggests that CEA is also essential for suppression of food intake (Cai et al, 2014; Carter et al, 2013) and for directing motivational behavior (Robinson et al, 2014), providing hence a possible hub for integrating survival circuits for fear and hunger. Interestingly, among the multiple neuromodulators that shape amygdala output, the neuropeptide $\mathrm{Y}$ system is involved in both feeding and fear. In particular, central NPY Y4 receptors that are targeted by peripherally 
released pancreatic polypeptide (PP) may link peripheral feeding-related signals to emotional processes in the brain (Holzer et al, 2012).

Experimentally, amygdala functioning and related fear learning can be tested by Pavlovian fear conditioning, in which a subject learns to associate an initially neutral stimulus, such as a tone (conditioned stimulus, CS), with an aversive stimulus, typically a mild electric food shock (unconditioned stimulus, US) (LeDoux, 2000). As a consequence, the presentation of the CS alone or the context (consisting of the conditioning environment, such as light, texture, or odor of the chamber) in which the fear memory was acquired will result in a species-specific fear reaction. Repetitive presentations of the CS in the absence of a shock, however, result in a reduction of the acquired fear reaction. This learning process is termed fear extinction and is the underlying principle of exposure therapy in human patients suffering from anxiety disorders (Davis, 2011; Herry et al, 2010; Myers and Davis, 2007; Ricardo and Koh, 1978).

Here, we provide evidence that the fear-related mechanisms controlled by amygdala circuitries are strongly correlated with those regulating food intake and energy balance. We further demonstrate that short-term fasting results in the suppression of fear by enhancing feed-forward inhibition in an amygdala microcircuit, whereas genetic deletion of the Y4 receptor reduced appetite and impaired fear extinction.

\section{MATERIALS AND METHODS}

\section{Animals}

Wild-type (WT) and Y4KO mice, both on a C57Bl/6NCrl background, were bred at the Institute of Pharmacology, Medical University of Innsbruck. All procedures involving animals and animal care were conducted in accordance with international laws and policies (Directive 2010/63/EU of the European parliament and of the council of 22 September 2010 on the protection of animals used for scientific purposes; Guide for the Care and Use of Laboratory Animals, US National Research Council, 2011) and were approved by the Austrian Ministry of Science. All effort was taken to minimize the number of animals used and their suffering.

\section{Behavioral Experiments}

Experiments were performed in adult male $\mathrm{C} 57 \mathrm{Bl} / 6 \mathrm{NCrl}$ mice (10-12 weeks old, weighing 22-28 g) during the light phase of the light/dark cycle. Y4KO mice were backcrossed for at least 10 generations to a $\mathrm{C} 57 \mathrm{Bl} / 6 \mathrm{NCrl}$ background. They were housed in groups of three to five animals under standard laboratory conditions $(12 \mathrm{~h} / 12 \mathrm{~h}$ light/dark cycle, lights on: 0700 hours, food and water ad libitum). Generation of Y4KO mice has been described in detail previously (Sainsbury et al, 2002; Tasan et al, 2009).

\section{Fear Conditioning}

Fear acquisition, context testing, and reinstatement were performed in context $\mathrm{A}$, consisting of a transparent acrylic rodent conditioning chamber with a metal grid floor that was enclosed by a sound attenuating chamber. Illumination for context A was $80 \mathrm{~lx}$ and the chambers were cleaned with $70 \%$ ethanol. Fear recall, fear extinction, extinction recall, and reinstatement testing were performed in a different context consisting of a dimly illuminated (10 lx) chamber with black walls and cleaned with $1 \%$ acetic acid (context B). On day 1 , mice were fear conditioned in context $\mathrm{A}$ by repetitive pairing of an auditory stimulus (CS, $30 \mathrm{~s}$ white noise, $80 \mathrm{~dB}$ ) with a mild electric foot shock (US, $2 \mathrm{~s}, 0.5 \mathrm{~mA}$ ). All animals received five CS, each of them coterminating with a US. On day 2, mice were tested for their context fear memory in context A ( $15 \mathrm{~min})$. Fear extinction (15 CS presentations, each $30 \mathrm{~s}$, interstimulus interval $5 \mathrm{~s}$ ) and extinction recall (5 CS presentations, each $30 \mathrm{~s}$, interstimulus interval $5 \mathrm{~s}$ ) were performed in context B on days 3 and 4, respectively. As Y4KO mice did not show fear extinction, we performed an extensive extinction protocol, consisting of 5 extinction sessions, with 15 CS each ( $30 \mathrm{~s}$, interstimulus interval $5 \mathrm{~s}$ ) and extinction recall was tested the following day (5 CS).

\section{Fasting Procedures}

Mice were fasted overnight for $16 \mathrm{~h}$ before fear acquisition, for fear conditioning experiments, and starting immediately after or $5 \mathrm{~h}$ after fear acquisition for $16 \mathrm{~h}$, for extinction experiments. For fasting, mice were single housed; food and bedding was removed but water was available ad libitum. Control mice were also single housed for the same time without bedding but with access to food and water ad libitum. Bedding was removed because mice that have no access to food tend to eat the bedding of the cage, which may trigger the activation of feeding-related neuronal circuits and release of hormones.

\section{Electrophysiology}

Slice electrophysiology was performed on acute slices $24 \mathrm{~h}$ after the final behavioral experiment. See Figure $4 \mathrm{~h}$ and Supplementary Information for details.

\section{Immunohistochemistry}

cFos, cFos/GABA, cFos/FOXP2, and $\mathrm{cFos} / \mathrm{PKC} \delta$ were performed as described previously in detail (Tasan et al, 2011). See Supplementary Information for details.

\section{Statistical Analysis}

Data are presented as means \pm SEM and were analyzed for normal distribution and equal variances using the GraphPad Prism 5 software (San Diego, CA). Fear-conditioning experiments were analyzed by repeated two-way ANOVA (time, genotype/treatment, interaction) and Bonferroni post hoc test for selected comparisons. One-way ANOVA with Bonferroni post hoc test was used to analyze changes in bodyweight and Mann-Whitney test for analyzing US sensitivity threshold.

\section{RESULTS}

\section{Short-Term Fasting Specifically Impairs Long-Term Memory but not Short-Term Memory of Cued and Context Fear}

To investigate the role of short-term fasting on the acquisition of conditioned fear, male C57BL/6N mice were 
a

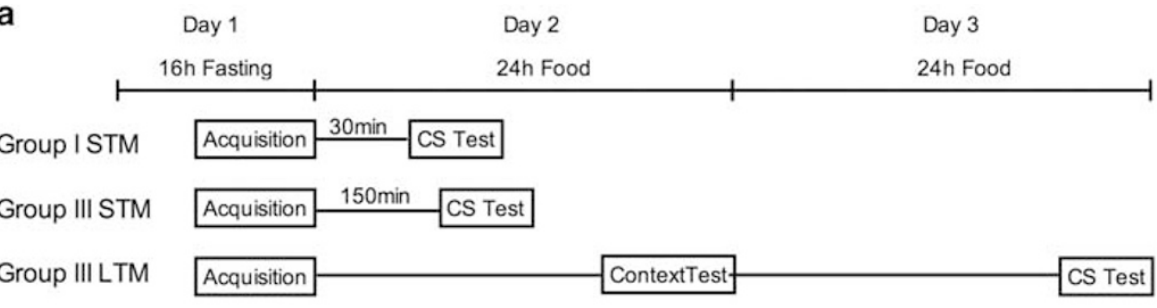

b

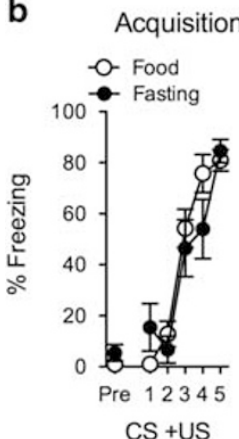

c

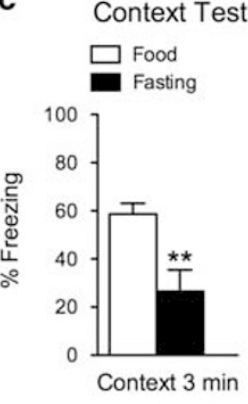

d

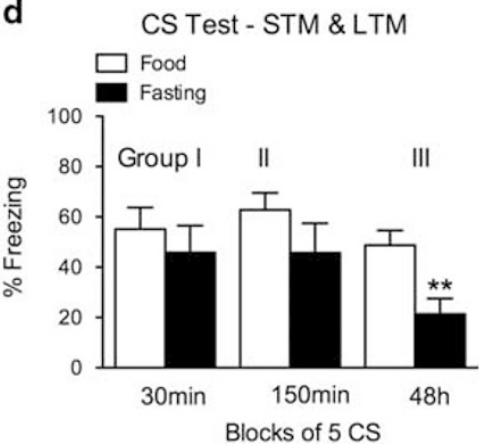

Figure I Acute short-term fasting before fear conditioning inhibits formation of context- and conditioned stimulus (CS)-induced long-term fear memory (LTM) while not affecting short-term memory (STM). (a) Fasting started $16 \mathrm{~h}$ before and continued during fear acquisition. All mice had access to food ad libitum after fear acquisition and before and during fear testing. (b) Both fasted and fed mice exhibited similar baseline freezing and acquisition of conditioned fear. (c) Reduced context freezing of mice that were fasted before and during fear acquisition. (d) Mice that were fasted before and during fear acquisition displayed reduced CS-induced freezing $48 \mathrm{~h}$ after fear conditioning, whereas STM tested 30 and I50 min after fear acquisition was similar to controls (repeated two-way analysis of variance (ANOVA) for acquisition, Student's $t$-test for context and CS testing, $* * P<0.01 ; L T M-$ food, $n=I I$, fasting: $n=I I$; STM 30 min - food: $n=6$, fasting: $n=6$; STM 150 min: food: $n=6$, fasting: $n=6$ ).

fasted overnight for $16 \mathrm{~h}$ before fear conditioning and their performance was compared with non-fasted littermates (Figure 1a). Short-term fasting resulted in a mean reduction of body weight by $17.4 \%$ (Supplementary Figure 1). Acquisition of conditioned fear was unchanged in fasted and non-fasted mice (Figure 1b, two-way ANOVA for repeated measurements: time $-\mathrm{F}_{(4,80)}=60.74, P<0.0001$, treatment $-\mathrm{F}_{(1,20)}=0.24, P>0.05$, interaction $\mathrm{F}_{(4,80)}=2.51$, $P>0.05$ ). Context fear memory, however (Figure 1c, $3 \mathrm{~min}$ context testing on day 2: $\left.t_{(20)}=3.21, P<0.01\right)$, tested $24 \mathrm{~h}$ after fear acquisition and refeeding by exposing the mice to the original conditioning chamber (context A), was significantly reduced, whereas context fear acquisition was unchanged (Supplementary Figure 2). Owing to reduced context fear expression, context extinction appeared to be facilitated in fasted mice compared with fed mice (Supplementary Figure 2, two-way ANOVA for repeated measurements: time $-\mathrm{F}_{(14,280)}=6.77, P<0.0001$, treatment $-\mathrm{F}_{(1,20)}=9.84, P<0.01$, interaction $\left.\mathrm{F}_{(14,280)}=0.45, P>0.05\right)$. Similarly, freezing to the CS under fed conditions, tested $48 \mathrm{~h}$ after fear acquisition by exposing mice to the auditory stimulus alone (CS test, long-term memory (LTM); Figure 1a $+d$ ) in a different chamber (context B), was significantly lower in mice that were fasted before fear acquisition (Figure 1d; $\left.t_{(20)}=3.20, \quad P<0.01\right)$. However, short-term memory (STM) tested (Figure $1 \mathrm{a}+\mathrm{d}$, CS test STM, under fed conditions) in separate groups of mice (Figure 1a) was similar in fasted and non-fasted mice, as demonstrated by CS-induced freezing 30 and $150 \mathrm{~min}$ after fear acquisition (Figure $1 \mathrm{~d} ; t_{(10)}=0.67, P>0.05$ and $t_{(10)}=1.26, P>0.05$, respectively). As the effect of fasting on fear memory developed slowly, we performed fear acquisition after $16 \mathrm{~h}$ of fasting and $24 \mathrm{~h}$ of refeeding, further demonstrating that fasting did not affect fear acquisition (Supplementary Figure 3). Collectively, these data suggest impaired consolidation or recall of conditioned fear in mice that were fasted before fear acquisition, whereas learning and STM remain unaffected.

\section{Short-Term Fasting Facilitates Extinction Learning and Promotes Extinction Recall}

To understand if fasting-induced inhibition of fear depends on memory consolidation and to investigate the effect of fasting on fear extinction, a separate group of mice was tested for fear recall after $16 \mathrm{~h}$ of fasting. Fasting was initiated here either immediately or $24 \mathrm{~h}$ after fear acquisition (Figure 2a). There was no change in CS-induced freezing during fear recall in mice that were fasted immediately or $24 \mathrm{~h}$ after fear acquisition compared with non-fasted controls, suggesting that fasting induced-changes develop slowly, over time (eg, 16h), and have to be present within the consolidation window to affect long-term fear memory. Interestingly, freezing to the CS upon fear recall was similar in animals that were fasted after fear acquisition and non-fasted controls (Figure $2 c ; t_{(16)}=0.38, P>0.05$ ), suggesting equal expression of fear in fasted and non-fasted mice. Fear extinction learning, however, was significantly facilitated in fasted mice (Figure 2d; two-way ANOVA for repeated measurements, time $-\mathrm{F}_{(24,432)}=9.03, \quad P<0.0001$, treatment $-\mathrm{F}_{(1,18)}=5.44$, $P<0.05$ and interaction $\left.\mathrm{F}_{(24,432)}=3.55, P<0.0001\right)$. More importantly, extinction recall, tested under fed conditions $24 \mathrm{~h}$ after fear extinction training, by exposing the mice to 5 CS in context B was still reduced in those mice that were fasted before extinction learning (Figure 2e; $t_{(16)}=3.61$, 

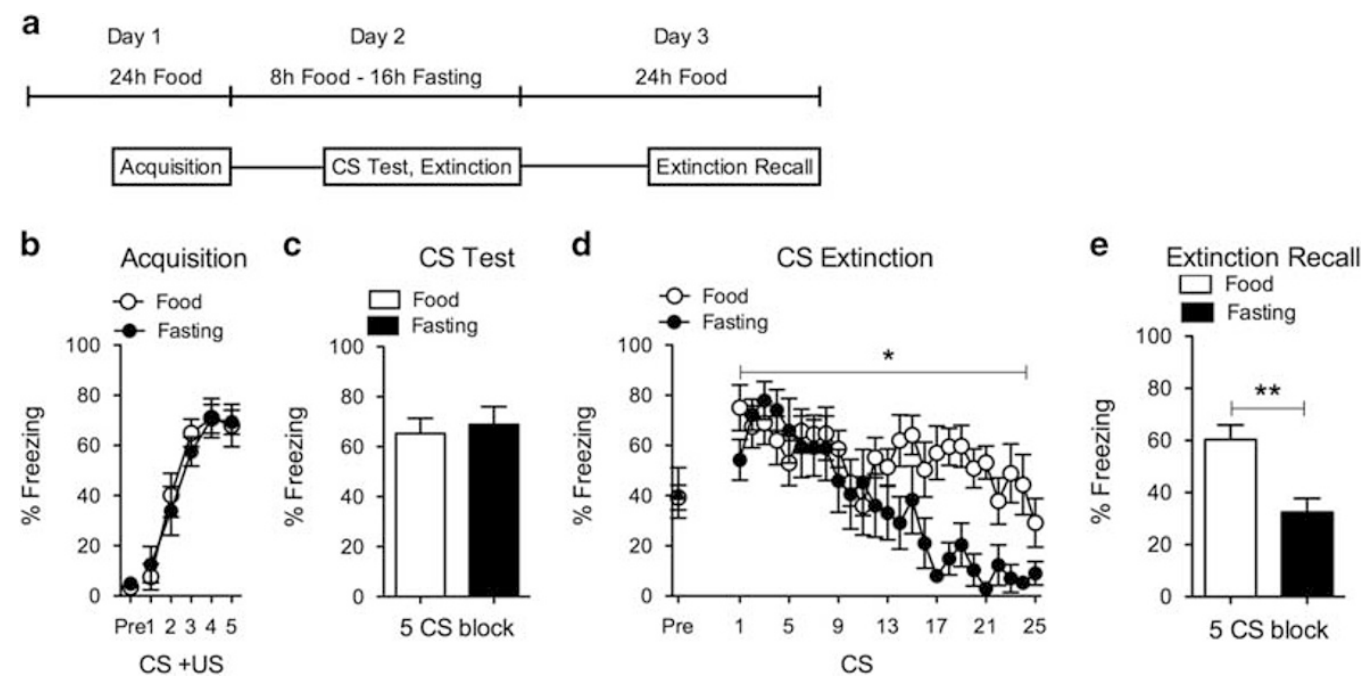

Figure 2 Short-term fasting before fear extinction improves extinction learning. (a) Following fear conditioning, mice were fasted for $16 \mathrm{~h}$ before and during extinction training. Extinction recall was tested $24 \mathrm{~h}$ later with food available ad libitum. (b) Following fear acquisition, mice were divided into two equal groups, one that was fasted and one with food available. (c) No difference in conditioned stimulus (CS) induced freezing was observed between fasted and non-fasted mice, (d) but facilitated fear extinction in mice that were fasted $16 \mathrm{~h}$ before and during fear extinction learning, and (e) reduced CS-induced freezing in extinction recall of mice that were fasted before and during extinction learning (repeated two-way analysis of variance (ANOVA) for acquisition and extinction learning, Student's $t$-test for CS-induced freezing and extinction recall testing, $* P<0.05$, ${ }^{*} * P<0.01$; Food: $n=10$, fasting: $n=10$ ).

$P<0.01)$. Taken together, these data indicate that $16 \mathrm{~h}$ of acute fasting does not alter learning in general, but rather modulates fear memory by specifically influencing the emotional valance of learning processes. Thus, fasting inhibits the consolidation of an acquired fear memory but promotes the acquisition and consolidation of fear extinction.

\section{Genetic Deletion of the Y4 Receptor Reduces Appetite and Impairs Fear Extinction}

If survival circuits, such as feeding and fear, were indeed influencing each other, we hypothesized that mice with altered feeding behavior or genetic ablation of feedingrelated genes would also display specific changes in fear extinction behavior (Gutman et al, 2008; Verma et al, 2012). Y4 receptors are expressed in the CNS and are activated by PP that is released from the pancreas in response to feeding. Interestingly, Y4KO mice display decreased body weight and reduced food intake, both suggesting chronic suppression of the hunger circuit (Lin et al, 2004; Sainsbury et al, 2002). To investigate the relation of a feeding-related gene and satiety to fear extinction, we subjected Y4KO mice to Pavolvian fear conditioning (Figure 3a). Acquisition (Figure 3b, two-way ANOVA for repeated measurements, time $-\mathrm{F}_{(4,48)}=27.29$, $P<0.0001$, genotype $-\mathrm{F}_{(1,12)}=2.54, \quad P>0.05$, interaction $\left.\mathrm{F}_{(4,48)}=1.28, \quad P>0.05\right)$ and recall of conditioned fear (Figure $3 c ; t_{(13)}=0.54, P>0.05$ ) were unchanged in $\mathrm{Y} 4 \mathrm{KO}$ mice compared with controls. Fear extinction, however, was significantly impaired in Y4KO mice (Figure 3d and e; two-way ANOVA for repeated measurements, time$\mathrm{F}_{(14,182)}=0.82, P>0.05$, genotype $-\mathrm{F}_{(1,13)}=26.90, P<0.001$, interaction $\mathrm{F}_{(14,182)}=3.08, \quad P<0.001$, and fear recall$\left.t_{(13)}=3.86, P<0.01\right)$, suggesting that genetic alterations in the feeding circuit considerably alter fear behavior. Sensitivity to the electric foot-shock was not different from controls (Supplementary Figure 4). These results suggest that modification of the feeding circuit has a significant impact on fear processing. In particular, dysregulated appetite correlated with impaired fear extinction.

\section{Short-Term Fasting Rescues Impaired Fear Extinction in Y4KO Mice}

Next, we tried to rescue the specifically impaired fear extinction in Y4KO mice by subjecting them to three cycles of extinction-recall sessions, each consisting of $16 \mathrm{~h}$ fasting before extinction training followed by extinction recall tested under fed conditions $24 \mathrm{~h}$ later (Figure $3 \mathrm{f}$ and Supplementary Figure 1 for reduction of body weight). CS-induced freezing in context $\mathrm{B}$ on the testing day was similar in fasted and fed Y4KO mice (Figure $3 \mathrm{~h} ; t_{(16)}=0.20, P>0.05$ ), indicating equal acquisition and expression of conditioned fear. Extinction learning, however, was significantly enhanced in Y4KO mice that were subjected to $16 \mathrm{~h}$ fasting compared with fed Y4KO mice (Figure 3i; two-way ANOVA for repeated measurements, time $-\mathrm{F}_{(24,168)}=0.72, P>0.05$, treatment $-\mathrm{F}_{(1,7)}=7.46, P<0.05$, interaction $\mathrm{F}_{(7,168)}=1.01$, $P>0.05)$. More importantly, this extinction memory was preserved upon refeeding, as demonstrated by the reduced freezing behavior during extinction recall in context $\mathrm{B}$ (Figure $3 \mathrm{j} ; t_{(7)}=1.63, P>0.05 ; t_{(7)}=2.55, P<0.05 ; t_{(7)}=4.84$, $P<0.01$ for extinction recalls 1,2 , and 3 , respectively), suggesting that impaired fear extinction can be rescued by modulation of the feeding circuit.

To investigate whether this reduction of fear was permanent, we subjected these mice 2 weeks after the last extinction trial to a reinstatement paradigm, consisting of one unsignaled foot-shock in context $\mathrm{A}$ and testing of CS-induced freezing in context B on days 20 and 21 , respectively (Figure 3f). Importantly, CS-induced freezing during reinstatement testing was still reduced in Y4KO mice that were repetitively fasted before extinction learning 
a

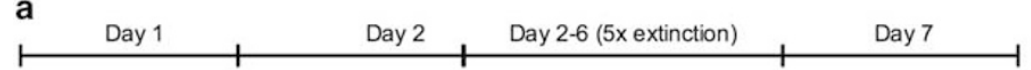

b

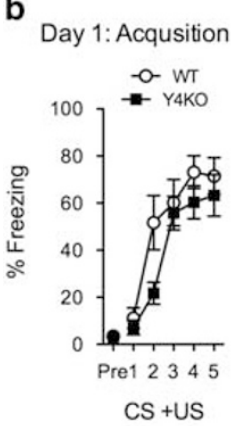

c

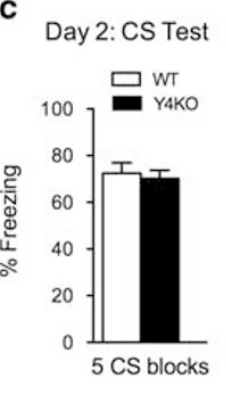

d

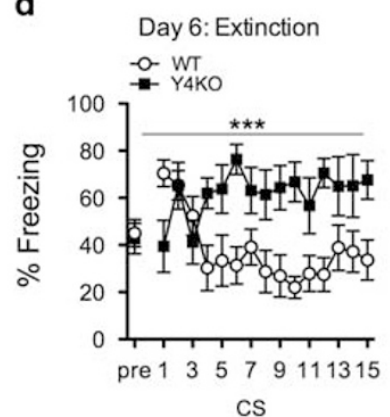

e

Day 7: Extinction recall

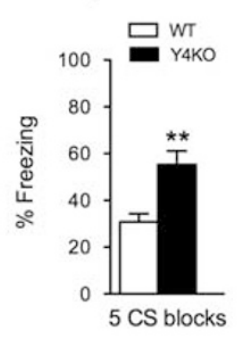

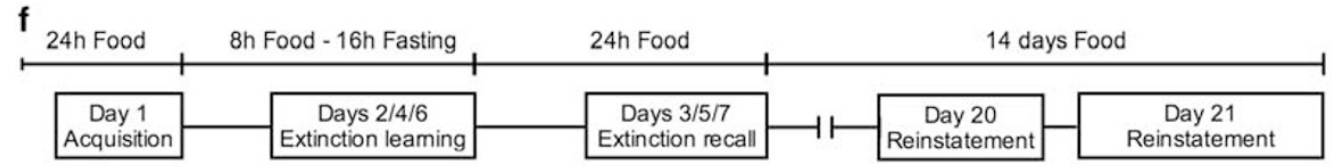

g

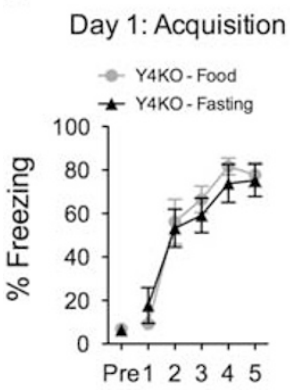

h

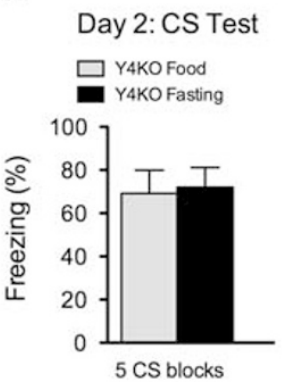

i

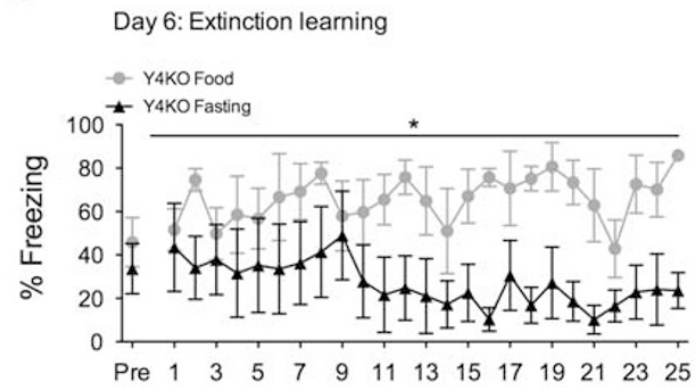

j

Day 3/5/7: Extinction Recall Day 21: Reinstatement Test

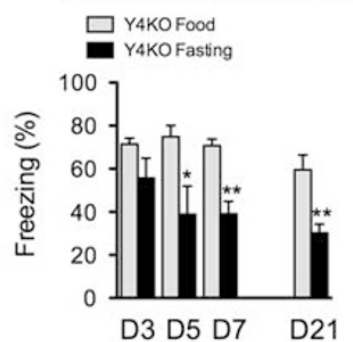

Figure 3 Impaired fear extinction in Y4 receptor knockout $(\mathrm{KO})$ mice was rescued by repeated fasting episodes before extinction learning. (a) Y4KO mice and wild-type controls were subjected to fear acquisition, conditioned stimulus (CS) testing $24 \mathrm{~h}$ later, and to a total of four extinction sessions on days 2-6, followed by extinction recall on day 7. (b) No difference in fear acquisition and (c) fear recall, but (d) impaired extinction learning (note the apparent reduction of freezing levels in Y4KO mice during CSI and 3, that was, however, due to jumping behavior, thus probably indicating an increased stress reaction) and (e) extinction recall in Y4KO mice compared with wild-type controls. (f) After fear acquisition, one group of Y4KO mice was subjected to repeated cycles of fasting before and during extinction learning followed by extinction recall under fed conditions. (g) Following fear acquisition, Y4KO mice were divided into two equal groups, one that was fasted before extinction training and one that was not, ( $h$ ) no difference in fear expression between fasted and non-fasted Y4KO mice, (i) rescued fear extinction in fasted Y4KO mice compared with fed Y4KO controls, (j) successive reduction of freezing in extinction recall on testing days 3, 5, and 7 tested under fed conditions and reduced reinstatement on day 21 in $Y 4 K O$ mice that were fasted before extinction training, suggesting permanent suppression of fear (repeated two-way analysis of variance (ANOVA) for acquisition and extinction learning, Student's t-test for CS-induced freezing and extinction recall and reinstatement testing, $* P<0.05$, ** $P<0.01$, *** $P<0.00$ I; WT vs Y4KO-WT: $n=9, Y 4 K O: n=6$ and $Y 4 K O$ fasted vs non-fasted-Y $4 \mathrm{KO}$ fasting: $n=8, Y 4 K O$ food: $n=8)$. KO, knock out.

(Figure $3 \mathrm{j} ; t_{(7)}=3.89, P<0.01$ ), suggesting a long-lasting, stress-resistant suppression of fear.

\section{Short-Term Fasting Specifically Activates Medial Intercalated Neurons and Facilitates Feed-Forward Inhibition from the Basolateral to the Centromedial Amygdala}

We next investigated the underlying synaptic correlates linking feeding and fear extinction circuits. Following fear acquisition, Y4KO mice were fasted for $16 \mathrm{~h}$, subjected to extinction training, and brains were processed for immunohistochemistry $90 \mathrm{~min}$ after the end of fear extinction training. Compared with non-fasted Y4KO mice (Figure 4a-c), expression of the immediate-early gene $c F o s$ was increased in those Y4KO mice that were fasted before extinction training
(Figure $4 \mathrm{~d}-\mathrm{f}$ ), specifically in the medial intercalated cells (mITCs), a brain nucleus associated with fear extinction (Busti et al, 2011; Likhtik et al, 2008) (Figure 4g; $t_{(14)}=2.60$, $P<0.05)$. Thus, short-term fasting activates specific neuronal populations in extinction-related brain areas.

As shown previously in rats, fear extinction results in enhanced feed-forward inhibition from the BLA to the CEm, mediated by increased activity of mITC neurons (Amano et al, 2010). To determine whether facilitated fear extinction of fasted mice corresponded to alterations in synaptic neurotransmission, we performed whole-cell patch-clamp recordings to measure BLA to CEm feed-forward inhibition in acute amygdala slices of mice $24 \mathrm{~h}$ after two extinction trainings. Stimulation of the BLA at intensities ranging from 100 to $500 \mu \mathrm{A}$ consistently evoked an IPSP in CEm neurons with an initial, brief EPSP component (Figure 4l). Compared 

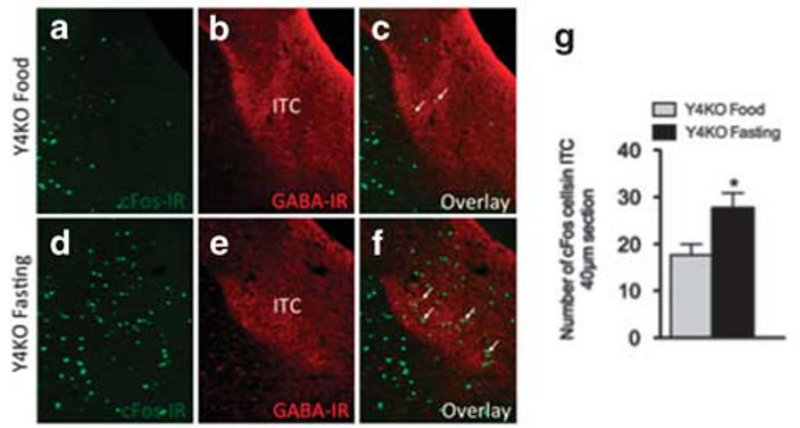

h

\begin{tabular}{|l|l|}
\hline WT/Y4KO Homecage Day 3 Electrophysiology \\
\hline Day 1-2 Homecage
\end{tabular}

\begin{tabular}{l|l|} 
WT/Y4KO Food + Ext & \multicolumn{1}{l|}{ Food } \\
\hline Day 1 Acquisition & Day 2 Extinction (2x) \\
\hline
\end{tabular}

Y4KO Fasting + Ext

\begin{tabular}{|c|c|c|}
\hline Food & $16 \mathrm{~h}$ Fasting & \multicolumn{1}{|c|}{ Food } \\
\hline Day 1 Acquisition & Day 2 Extinction (2x) & Day 3 Electrophysiology \\
\cline { 1 - 2 } & &
\end{tabular}

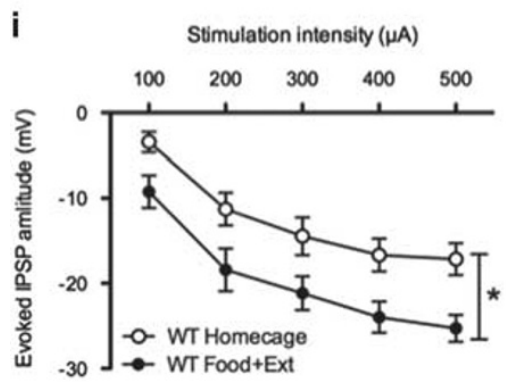

j

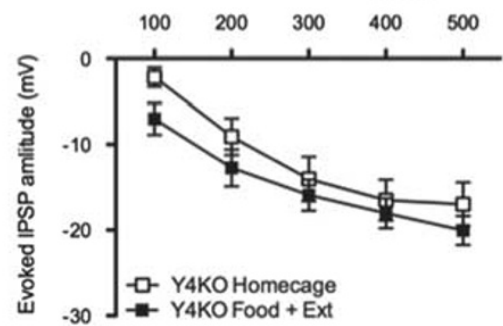

k
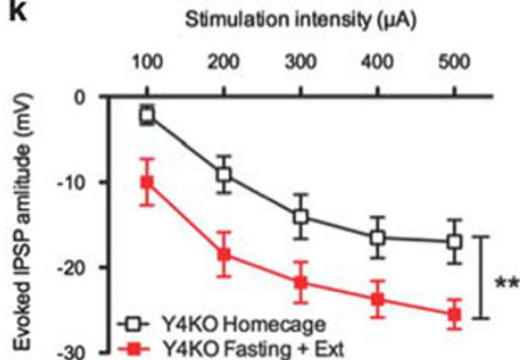
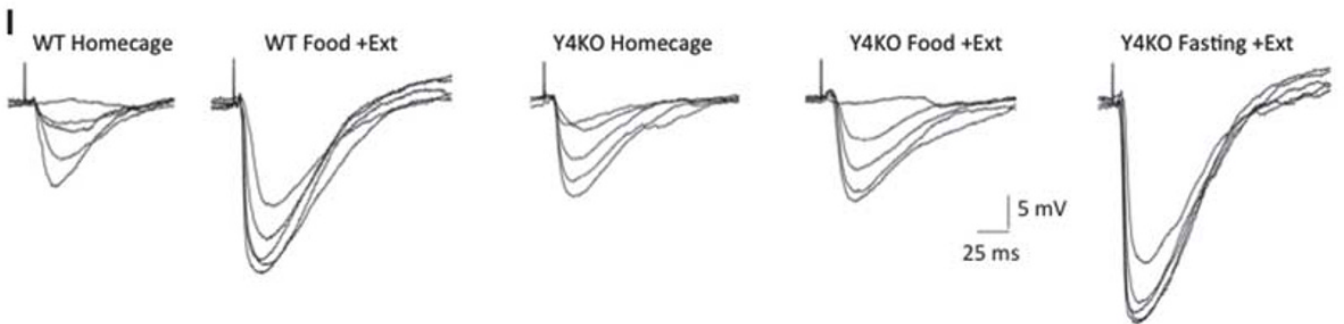

Figure 4 Fasting in Y4KO mice results in activation of the medial intercalated cell ( $\mathrm{m} / \mathrm{TC}$ ) and enhanced basolateral amygdala (BLA) to centromedial amygdala (CEm) feed-forward inhibition. (a-c) Expression of immediate-early gene cFos in the ITC of a fasted Y4KO compared with ( $d-f$ ), a non-fasted Y4KO control reveals $(\mathrm{g})$ increased activation of ITC neurons, (h) experimental setup for ex vivo electrophysiology indicating home-cage controls, wild-type (WT) and $\mathrm{Y} 4 \mathrm{KO}$ undergoing fear acquisition on day I, extinction on day 2, and electrophysiology on day 3 under fed conditions and experimental group with a $16 \mathrm{~h}$ fasting period before and during extinction training, (i) enhanced feed-forward inhibition from BLA to CEm via mITC in WT mice after successful fear extinction, (j) lack of increased feed-forward inhibition in fed $Y 4 K O$ after extinction training corresponding to impaired fear extinction and ( $k$ ) rescue of impaired fear extinction in Y4KO mice by fasting facilitates enhanced feed-forward inhibition between BLA and CEm. (I) Example traces from WT and Y4KO mice of the individual groups with increasing stimulation intensities ( $n=W T$ home cage 4 mice, 12 cells; WT food+Ext 4 mice, 15 cells; Y4KO home cage 5 mice, 13 cells; Y4KO food+Ext 4 mice, 14 cells; Y4KO fasting+Ext 4 mice, 12 cells; $* P<0.05$, two-way analysis of variance (ANOVA) for repeated measurements for electrophysiology, and $Y 4 K O$ food: $n=8, Y 4 K O$ fasting: $n=8$; Student's $t$ test for c-Fos immunohistochemistry). $K O$, knock out.

with untrained $\mathrm{C} 57 \mathrm{BL} / 6 \mathrm{~N}$ mice (WT home cage), the amplitude of IPSPs was increased $24 \mathrm{~h}$ after successful fear extinction (Figure 4i; two-way ANOVA $\mathrm{F}_{(2,36)}=4.93$, $P<0.01)$. Bath application of the AMPA receptor antagonist, DNQX, abolished both the IPSP and EPSP (Supplementary Figure 5A), whereas application of GABA receptor antagonist, picrotoxin, completely blocked the IPSP. These data confirm that fear extinction results in enhanced feed-forward inhibition in an amygdala microcircuit connecting the BLA with the CEm.

In Y4KO mice (home cage), similar as in WT mice, electrical stimulation of the BLA consistently evoked a brief EPSP, followed by a larger IPSP in CEm neurons (Figure 4l). The amplitude of evoked IPSPs did not significantly differ between untrained fed or fasted Y4KO mice (both home cage), or Y4KO mice that underwent fear acquisition (Supplementary Figures 5B-D). However, in contrast to wild-type mice, and in line with the impaired fear extinction of Y4KO mice, feed-forward inhibition from BLA to CEm neurons also remained unchanged in Y4KO mice $24 \mathrm{~h}$ after two consecutive fear extinction trainings (Figure 4j). However, CEm neurons recorded from Y4KO mice that were fasted for $16 \mathrm{~h}$ before the two fear extinction trainings, and thus had successfully acquired extinction memory, exhibited larger IPSPs in response to BLA stimulation (Figure 4k; twoway ANOVA $\left.\mathrm{F}_{4,60}=2.90, P<0.05\right)$. As fasted $\mathrm{Y} 4 \mathrm{KO}$ mice displayed reduced freezing levels already after two extinction sessions (Figure 3j), we decided to perform electrophysiological recordings after the second extinction. No changes in general membrane properties were observed (Supplementary Figure 6). These data suggest that the impaired fear extinction in Y4KO mice is owing to the lack of inhibitory synaptic plasticity in BLA to CEm projections and that fasting before fear extinction rescues fear extinction by specifically activating medial ITC neurons, leading to a marked increase in BLA to CEm feed-forward inhibition. 


\section{DISCUSSION}

Here, we demonstrated that short-term fasting differentially affects fear and fear extinction learning. This differential effect on two fear-related learning processes suggests that the effect of acute fasting on fear was not a uniform inhibition or promotion of learning and memory per se. It rather indicates that short-term fasting manipulates these memories toward a reduction of fear. This is interesting in the light of an evolutionarily-conserved mechanism that adapts explorative behavior depending on internal homeostatic demand. Thus, in situations of increased hunger a subject will be prepared to take a higher risk, whereas in a saturated state safety concerns will predominate.

Furthermore, we demonstrated that genetic deletion of the Y4 receptor impaired fear extinction, an effect that was rescued by short-term fasting. PP that is released peripherally upon food intake serves as the main ligand for Y4 receptors (Holzer et al, 2012). In the brain, Y4 receptors are localized in specific areas that are in part open to the blood-brain barrier, such as hypothalamus and brain stem (Tasan et al, 2009). These brain regions are tightly integrated into the ascending reticular-activating system that may provide the necessary arousal for successful fear extinction. In particular, $\beta$-adrenoreceptor-dependent activation of the nucleus tractus solitarii (NTS) is essential for amygdala activation and respective memory formation (McGaugh, 2004; Mueller et al, 2008). Interestingly, Y4 receptors are highly expressed in the NTS and peripheral PP injection results in fast activation of NTS neurons (Tasan et al, 2009). Furthermore, a reduction of adrenergic tonus and sympathetic activity has been reported in Y4KO mice (Smith-White et al, 2002). Thus, deletion of Y4 receptors in the NTS may inhibit extinction learning by dampening the necessary arousal. On the other hand, short-term fasting may have rescued fear extinction in Y4KO mice by alternative activation systems and release of stress hormones (McGaugh, 2004).

Besides PP, NPY also displays affinity for central Y4 receptors at nanomolar concentrations (Bard et al, 1995; Gehlert et al, 1996), suggesting that central Y4 receptors may be either targeted by peripherally released PP or by central NPY. Expression of the immediate-early gene cFos demonstrated that short-term fasting specifically activates AGRP/ NPY neurons in the arcuate nucleus of the hypothalamus (Supplementary Figure 7). Although activation of some arcuate AGRP/NPY neuron projections promote food intake others do not (Betley et al, 2013; Wu et al, 2009). In particular, AGRP/NPY neurons that are projecting to limbic areas, such as the amygdala, may be crucial for adapting emotional behaviors to the internal homeostatic situation. This could also be achieved by NPY release that is involved in both regulating feeding and reducing anxiety (Bacchi et al, 2006; Kask et al, 2002; Tasan et al, 2010). Recent evidence demonstrated that NPY suppresses the expression of conditioned fear and promotes fear extinction (Fendt et al, 2009; Gutman et al, 2008; Lach and de Lima, 2013), extending the anxiolytic properties of NPY to models of learned fear. In fact, similar to Y4KO mice, NPYKO mice also fail to extinguish learned fear (Verma et al, 2012), further emphasizing the central role of feeding-related genes in the modulation of fear extinction. In our experiments, the extensive activation of AGRP/NPY neurons and the consecutive release of NPY upon fasting may have significantly contributed to the facilitated extinction learning. Furthermore, NPY is released from a considerable number of amygdala interneurons, and injection of NPY into the BLA may facilitate fear extinction (Gutman et al, 2008).

The amygdala complex is crucially involved in mediating fear- and anxiety-related behaviors (Pape and Pare, 2010; Quirk and Mueller, 2008). This is achieved by extensive reciprocal connections with hypothalamus, brain stem, and cortical areas. Short-term fasting results in a drop of glucose levels, activation of the autonomic nervous system, and release of stress hormones. This general activation is important, as a certain degree of arousal is essential for successful fear extinction (McGaugh, 2004). For instance, targeting the catecholaminergic system by yohimbine or LDOPA, but also release of stress hormones, such as glucocorticoids, have been shown to facilitate fear extinction learning in rodents and humans (Fitzgerald et al, 2014; Holmes and Quirk, 2010; McGuire et al, 2014; Soravia et al, 2006). The duration of the fasting period may be a crucial factor. Although prolonged fasting ( $24 \mathrm{~h}$ and more) resulted in facilitated extinction it also increased freezing behavior to the first CS, probably by augmenting stress levels. On the other hand, shorter fasting periods may not provide the necessary motivation to reduce fear. Thus, fasting may trigger the synchronous release of different neuromodulators and hormones that ultimately promote synaptic plasticity in the amygdala as the central stage for fear and extinction learning. Specifically, using cFos mapping, our experiments indicate that the interaction of fear and hunger takes place on the level of the amygdala and more precisely in the medial intercalated neurons. These neurons are extensively activated after successful extinction learning (Busti et al, 2011), whereas ablation of the mITCs completely abolishes consolidation of fear extinction (Likhtik et al, 2008). Recently, the electrophysiological correlate of fear extinction has been pinpointed to an amygdala microcircuit connecting the BLA with the CEm via mITC (Amano et al, 2010). Here, we investigated this microcircuit in the mouse brain and demonstrated that short-term fasting before extinction training activates inhibitory neurons in the mITCs projecting to the main output nucleus of the amygdala, the CEm, with a concomitant increase in feed-forward inhibition from the BLA and improved extinction memory. Taken together with the reduced freezing behavior during extinction recall tested under fed conditions, these results confirm that short-term fasting does not unspecifically increase locomotion, but rather promotes extinction learning by activating mITCs in an extinction-relevant amygdala microcircuit.

It is important to note that fasting affects both context fear and fear extinction, two phenomena that are sensitive to environmental encoding and hippocampal damage (Corcoran et al, 2005; Hobin et al, 2006). The hippocampus modulates fear behavior by direct connections to the amygdala or indirectly via activation of the prefrontal cortex (Maren, 2005). Interestingly, the infralimbic region of the prefrontal cortex activates inhibitory intercalated neurons (Amir et al, 2011; Pinard et al, 2012), a population of neurons that were activated in our experiments by shortterm fasting and consequently reduced CEm activation by feed-forward inhibition (Supplementary Figure 8). 
Fear memories are strong and often persist lifelong, whereas extinction memories are rather labile and transient, resulting in relapse of fear, in particular, under stressful situations (Ji and Maren, 2007; Quirk and Mueller, 2008). Here, we demonstrate that short-term fasting before fear extinction not only rescues impaired fear extinction in $\mathrm{Y} 4 \mathrm{KO}$ mice but more importantly results in a permanent suppression of fear, even under stressful situations. Given that treating human anxiety disorders by exposure therapy is not equally effective in all patients and relieves symptoms only temporarily, an efficient supportive treatment is required. Our results indicate that genetic deletion of genes that reduce appetite may also impair fear extinction and that bypassing the circuit, for example, by increasing appetite through periods of mild fasting, can rescue impaired fear extinction. Thus, fasting before exposure therapy may be a valuable supportive therapeutic option with fast translation into clinics and may be well accepted by patients. Furthermore, the molecular machinery of the feeding circuit may provide novel targets for pharmacological treatment of anxiety disorders.

\section{FUNDING AND DISCLOSURE}

There are no personal financial holdings of any of the authors that could be perceived as constituting a potential conflict of interest.

\section{ACKNOWLEDGMENTS}

This work was supported by the Austrian Science Fund (FWF, P 22830-B18, to RT) and the Tiroler Wissenschaftsfond (TWF, GZ: UNI_0404/1479 to RT). GL was also funded by a "Ciências Sem Fronteiras" fellowship (BEX-2439-13-1). The manuscript was prepared by DV, JW, GL, GS, and RT. We thank Elisabeth Gasser and Anneliese Bukovac for technical assistance and Prof. Heide Hörtnagl for discussion.

\section{REFERENCES}

Amano T, Unal CT, Pare D (2010). Synaptic correlates of fear extinction in the amygdala. Nat Neurosci 13: 489-494.

Amir A, Amano T, Pare D (2011). Physiological identification and infralimbic responsiveness of rat intercalated amygdala neurons. J Neurophysiol 105: 3054-3066.

Atasoy D, Betley JN, Su HH, Sternson SM (2012). Deconstruction of a neural circuit for hunger. Nature 488: 172-177.

Bacchi F, Mathe AA, Jimenez P, Stasi L, Arban R, Gerrard P et al (2006). Anxiolytic-like effect of the selective Neuropeptide Y Y2 receptor antagonist BIIE0246 in the elevated plus-maze. Peptides 27: 3202-3207.

Balleine BW (2005). Neural bases of food-seeking: affect, arousal and reward in corticostriatolimbic circuits. Physiol Behav 86: 717-730.

Bard JA, Walker MW, Branchek TA, Weinshank RL (1995). Cloning and functional expression of a human Y4 subtype receptor for pancreatic polypeptide, neuropeptide $\mathrm{Y}$, and peptide YY. J Biol Chem 270: 26762-26765.

Betley JN, Cao ZF, Ritola KD, Sternson SM (2013). Parallel, redundant circuit organization for homeostatic control of feeding behavior. Cell 155: 1337-1350.

Busti D, Geracitano R, Whittle N, Dalezios Y, Manko M, Kaufmann $\mathrm{W}$ et al (2011). Different fear states engage distinct networks within the intercalated cell clusters of the amygdala. J Neurosci 31: 5131-5144.
Cai H, Haubensak W, Anthony TE, Anderson DJ (2014). Central amygdala PKC-delta(+) neurons mediate the influence of multiple anorexigenic signals. Nat Neurosci 17: 1240-1248.

Carter ME, Soden ME, Zweifel LS, Palmiter RD (2013). Genetic identification of a neural circuit that suppresses appetite. Nature 503: $111-114$.

Corcoran KA, Desmond TJ, Frey KA, Maren S (2005). Hippocampal inactivation disrupts the acquisition and contextual encoding of fear extinction. J Neurosci 25: 8978-8987.

Davis M (2011). NMDA receptors and fear extinction: implications for cognitive behavioral therapy. Dialog Clin Neurosci 13: 463-474.

Ehrlich I, Humeau Y, Grenier F, Ciocchi S, Herry C, Luthi A (2009). Amygdala inhibitory circuits and the control of fear memory. Neuron 62: 757-771.

Fendt M, Burki $\mathrm{H}$, Imobersteg S, Lingenhohl K, McAllister $\mathrm{KH}$, Orain D et al (2009). Fear-reducing effects of intra-amygdala neuropeptide $Y$ infusion in animal models of conditioned fear: an NPY Y1 receptor independent effect. Psychopharmacology (Berl) 206: 291-301.

Fitzgerald PJ, Seemann JR, Maren S (2014). Can fear extinction be enhanced? A review of pharmacological and behavioral findings. Brain Res Bull 105: 46-60.

Gehlert DR, Schober DA, Beavers L, Gadski R, Hoffman JA, Smiley DL et al (1996). Characterization of the peptide binding requirements for the cloned human pancreatic polypeptidepreferring receptor. Mol Pharmacol 50: 112-118.

Gutman AR, Yang Y, Ressler KJ, Davis M (2008). The role of neuropeptide $\mathrm{Y}$ in the expression and extinction of fearpotentiated startle. J Neurosci 28: 12682-12690.

Herry C, Ferraguti F, Singewald N, Letzkus JJ, Ehrlich I, Luthi A (2010). Neuronal circuits of fear extinction. Eur J Neurosci 31: 599-612.

Hirano Y, Masuda T, Naganos S, Matsuno M, Ueno K, Miyashita T et al (2013). Fasting launches CRTC to facilitate long-term memory formation in Drosophila. Science 339: 443-446.

Hobin JA, Ji J, Maren S (2006). Ventral hippocampal muscimol disrupts context-specific fear memory retrieval after extinction in rats. Hippocampus 16: 174-182.

Holmes A, Quirk GJ (2010). Pharmacological facilitation of fear extinction and the search for adjunct treatments for anxiety disorders-the case of yohimbine. Trends Pharmacol Sci 31: 2-7.

Holzer P, Reichmann F, Farzi A (2012). Neuropeptide Y, peptide YY and pancreatic polypeptide in the gut-brain axis. Neuropeptides 46: 261-274.

Ji J, Maren S (2007). Hippocampal involvement in contextual modulation of fear extinction. Hippocampus 17: 749-758.

Kask A, Harro J, von Horsten S, Redrobe JP, Dumont Y, Quirion R (2002). The neurocircuitry and receptor subtypes mediating anxiolytic-like effects of neuropeptide Y. Neurosci Biobehav Rev 26: $259-283$.

Lach G, de Lima TC (2013). Role of NPY Y1 receptor on acquisition, consolidation and extinction on contextual fear conditioning: dissociation between anxiety, locomotion and non-emotional memory behavior. Neurobiol Learn Mem 103: 26-33.

LeDoux JE (2000). Emotion circuits in the brain. Annu Rev Neurosci 23: $155-184$.

LeDoux JE (2012). Evolution of human emotion: a view through fear. Prog Brain Res 195: 431-442.

Likhtik E, Popa D, Apergis-Schoute J, Fidacaro GA, Pare D (2008). Amygdala intercalated neurons are required for expression of fear extinction. Nature 454: 642-645.

Lin S, Boey D, Herzog H (2004). NPY and Y receptors: lessons from transgenic and knockout models. Neuropeptides 38: 189-200.

Maren S (2005). Synaptic mechanisms of associative memory in the amygdala. Neuron 47: 783-786.

McGaugh JL (2004). The amygdala modulates the consolidation of memories of emotionally arousing experiences. Annu Rev Neurosci 27: 1-28. 
McGuire JF, Lewin AB, Storch EA (2014). Enhancing exposure therapy for anxiety disorders, obsessive-compulsive disorder and post-traumatic stress disorder. Expert Rev Neurother 14: 893-910.

Mueller D, Porter JT, Quirk GJ (2008). Noradrenergic signaling in infralimbic cortex increases cell excitability and strengthens memory for fear extinction. J Neurosci 28: 369-375.

Myers KM, Davis M (2007). Mechanisms of fear extinction. Mol Psychiatry 12: 120-150.

Pape HC, Pare D (2010). Plastic synaptic networks of the amygdala for the acquisition, expression, and extinction of conditioned fear. Physiol Rev 90: 419-463.

Pinard CR, Mascagni F, McDonald AJ (2012). Medial prefrontal cortical innervation of the intercalated nuclear region of the amygdala. Neuroscience 205: 112-124.

Placais PY, Preat T (2013). To favor survival under food shortage, the brain disables costly memory. Science 339: 440-442.

Quirk GJ, Mueller D (2008). Neural mechanisms of extinction learning and retrieval. Neuropsychopharmacology 33: $56-72$.

Ricardo JA, Koh ET (1978). Anatomical evidence of direct projections from the nucleus of the solitary tract to the hypothalamus, amygdala, and other forebrain structures in the rat. Brain Res 153: 1-26.

Robinson MJ, Warlow SM, Berridge KC (2014). Optogenetic excitation of central amygdala amplifies and narrows incentive motivation to pursue one reward above another. J Neurosci 34: 16567-16580.

Sainsbury A, Schwarzer C, Couzens M, Jenkins A, Oakes SR, Ormandy CJ et al (2002). Y4 receptor knockout rescues fertility in ob/ob mice. Genes Dev 16: 1077-1088.

Smith-White MA, Herzog H, Potter EK (2002). Cardiac function in neuropeptide Y Y4 receptor-knockout mice. Regul Pept 110: 47-54.

Sohn JW, Elmquist JK, Williams KW (2013). Neuronal circuits that regulate feeding behavior and metabolism. Trends Neurosci 36: 504-512.
Soravia LM, Heinrichs M, Aerni A, Maroni C, Schelling G, Ehlert U et al (2006). Glucocorticoids reduce phobic fear in humans. Proc Natl Acad Sci USA 103: 5585-5590.

Sternson SM (2013). Hypothalamic survival circuits: blueprints for purposive behaviors. Neuron 77: 810-824.

Tasan RO, Bukovac A, Peterschmitt YN, Sartori SB, Landgraf R, Singewald $\mathrm{N}$ et al (2011). Altered GABA transmission in a mouse model of increased trait anxiety. Neuroscience 183: 71-80.

Tasan RO, Lin S, Hetzenauer A, Singewald N, Herzog H, Sperk G (2009). Increased novelty-induced motor activity and reduced depression-like behavior in neuropeptide Y (NPY)-Y4 receptor knockout mice. Neuroscience 158: 1717-1730.

Tasan RO, Nguyen NK, Weger S, Sartori SB, Singewald N, Heilbronn $\mathrm{R}$ et al (2010). The central and basolateral amygdala are critical sites of neuropeptide $\mathrm{Y} / \mathrm{Y} 2$ receptor-mediated regulation of anxiety and depression. J Neurosci 30: 6282-6290.

Verma D, Tasan RO, Herzog H, Sperk G (2012). NPY controls fear conditioning and fear extinction by combined action on $\mathrm{Y}(1)$ and $\mathrm{Y}(2)$ receptors. Br J Pharmacol 166: 1461-1473.

Williams KW, Elmquist JK (2012). From neuroanatomy to behavior: central integration of peripheral signals regulating feeding behavior. Nat Neurosci 15: 1350-1355.

Wu Q, Boyle MP, Palmiter RD (2009). Loss of GABAergic signaling by AgRP neurons to the parabrachial nucleus leads to starvation. Cell 137: 1225-1234.

(c) (i) () $\odot$ This work is licensed under a Creative Commons Attribution-NonCommercial-NoDerivs $\quad 4.0$ International License. The images or other third party material in this article are included in the article's Creative Commons license, unless indicated otherwise in the credit line; if the material is not included under the Creative Commons license, users will need to obtain permission from the license holder to reproduce the material. To view a copy of this license, visit http://creativecommons.org/licenses/by-nc-nd/4.0/

Supplementary Information accompanies the paper on the Neuropsychopharmacology website (http://www.nature.com/npp) 